\title{
Effect of Streptozotocin-induced Diabetes on GLUT-4 Phosphorylation in Rat Adipocytes
}

\author{
Najma Begum and Boris Draznin \\ Department of Medicine and Research Service, Veterans Affairs Medical Center, and University of Colorado \\ Health Sciences Center, Denver, Colorado 80220
}

\begin{abstract}
We have examined the regulation of GLUT-4 phosphorylation in adipocytes isolated from diabetic rats. Despite progressive $(40-70 \%)$ reductions in GLUT-4 protein contents on the 2 nd, 7th, and 14th day of diabetes, the phosphorylation of GLUT-4 was increased two- to fourfold. These alterations were accompanied by concomitant reductions $(40-66 \%)$ in the insulin-stimulated 2-deoxyglucose transport. Insulin treatment of diabetic animals for $5 \mathrm{~d}$ restored glucose transport activity, GLUT-4 protein, and GLUT-4 phosphorylation to control levels whereas vanadate and phlorizin were ineffective. In control adipocytes, insulin promoted GLUT-4 translocation from the low density microsomal (LDM) pool to the plasma membranes (PM) and decreased the state of GLUT-4 phosphorylation. In adipocytes isolated from the diabetic rats, insulin failed to stimulate GLUT- 4 translocation and to decrease GLUT-4 phosphorylation. To explore the mechanism of the diabetes-induced increases in the GLUT-4 phosphorylation, we investigated phosphoserine phosphatase (PSPase) activities using ${ }^{32} \mathrm{P}$-labeled GLUT- 4 and phosphorylase " $a$ " as substrates. Diabetes resulted in 50-60\% increase in the particulate PSPase activity and concomitant reductions in cytosolic PSPase activities. Although reduced cytosolic PSPase activity correlated with an inadequate dephosphorylation of LDM GLUT-4, the existence of highly phosphorylated PM GLUT-4 in the presence of increased particulate PSPase activity required additional explanation. To address this problem, we used PM GLUT-4 from diabetic rats as a substrate of particulate PSPase. Highly active diabetic particulate PSPase, which dephosphorylated control GLUT-4 and phosphorylase a, failed to dephosphorylate PM GLUT -4 from diabetic rats. These data suggest that PM GLUT-4 from diabetic rats is unable to interact with PSPase or that its phosphorylation sites are not accessible to PSPase action. In summary, an induction of diabetes with streptozotocin resulted in significant increases in GLUT-4 phosphorylation. In contrast to normal cells, insulin failed to promote GLUT-4 recruitment to the plasma membranes and its dephosphorylation in diabetic adipocytes. At the same time, diabetes appears to induce redistribution of PSPases, resulting in lower cytosolic activity and higher particulate activity. It also appears that the existence of highly phosphorylated GLUT -4 in the plasma membranes of diabetic adipocytes resulted from its inability to
\end{abstract}

Address correspondence to Dr. Boris Draznin, Section of Endocrinology $(111 \mathrm{H})$, Veterans Affairs Medical Center, 1055 Clermont Street, Denver, CO 80220.

Received for publication 4 November 1991 and in revised form 2 March 1992.

The Journal of Clinical Investigation, Inc.

Volume 90, October 1992, 1254-1262 interact with particulate PSPases. (J. Clin. Invest. 1992. 90:1254-1262.) Key words: insulin • translocation • glucose transport $\cdot$ GLUT-4 $\bullet$ protein

\section{Introduction}

In adipocytes and skeletal muscle cells, insulin stimulates glucose transport by promoting translocation of glucose transporters (GLUT-4) from the intracellular pool to the plasma membranes and by increasing their intrinsic activity (1-3). In streptozotocin-induced diabetes in rats as well as noninsulin-dependent diabetes in humans, there appears to be a reduction in the size of the intracellular pool of transporters (4-8). Moreover, there is a clear diminution in the ability of insulin to recruit GLUT-4 to the plasma membranes and to enhance their intrinsic activity $(9,10)$. The mechanism of this diabetes-induced insulin resistance (which is reversible with insulin therapy) remains incompletely understood.

One possibility is that alterations in the phosphorylation of GLUT-4 may impair its functioning. Although insulin does not appear to phosphorylate GLUT-4 to promote glucose transport $(11,12)$, other agents that increase its phosphorylation (i.e., isoproterenol, okadaic acid, high levels of cytosolic $\mathrm{Ca}^{2+}$ ) decrease insulin-stimulated glucose uptake $(13,14)$. We hypothesized that excessive phosphorylation of GLUT-4 may interfere with its responsiveness to stimulation by insulin. Since insulin activates several intracellular enzymes (e.g., glycogen synthase, pyruvate dehydrogenase) by promoting their dephosphorylation, it is possible that insulin exerts a similar effect on GLUT-4. Thus, in the case of insulin deficiency, GLUT-4 may not undergo adequate dephosphorylation and would remain in a phosphorylated (possibly less active) state.

We tested this hypothesis by investigating the state of phosphorylation of GLUT-4 in adipocytes of streptozotocin-diabetic rats. To address the mechanism(s) of possible alterations, we examined the effect of diabetes on phosphoserine phosphatase activity (PSPase) ${ }^{1}$ and its ability to dephosphorylate GLUT-4.

\section{Methods}

$\gamma\left[{ }^{32} \mathrm{P}\right]$ ATP $\left(\mathrm{sp}\right.$ act $>4,000 \mathrm{Ci} / \mathrm{mmol}$ ), $\left[{ }^{32} \mathrm{P}\right]$ orthophosphoric acid, and $\left[{ }^{3} \mathrm{H}\right] 2$ deoxyglucose were purchased from ICN Biochemical Division, ICN Biomedicals, Inc. (Costa Mesa, CA). Porcine insulin was a kind gift from Eli Lilly and Company (Indianapolis, IN). Collagenase

1. Abbreviations used in this paper: cAMP, cyclic AMP; CF, cystolic fraction; IGF II, insulin-like growth factor II; LDU, low density microsomal; PF, particulate fraction; PM, plasma membrane; PP-1, protein phosphatase 1; PP-2A, protein phosphatase 2A; PSPase, phosphoserine phosphatase; STZ, streptozotocin. 
was obtained from Worthington Biochemical Corporation (Freehold, $\mathrm{NJ})$. Reagents for SDS-PAGE and immunoblotting were purchased from Bio-Rad Laboratories (Richmond, CA). Streptozotocin (STZ), sodium orthovanadate, glycogen synthase, ATP, protein kinase A catalytic subunit, phosphorylase " $b$," phosphorylase kinase, DTT, PMSF, leupeptin, benzamidine, pepstatin A, aprotinin, antipain, soya trypsin inhibitor, phlorizin, sodium fluoride, sodium pyrophosphate, cytochrome C, NADPH, anti-mouse IgG-agarose, Triton X-100, SDS, and kit for 5'-nucleotidase were purchased from Sigma Chemical Co. (St. Louis, MO). Prepacked Sephadex G-25 columns were procured from Pharmacia Fine Chemicals (Piscataway, NJ). Anti-mouse glucose transporter (GLUT-4, IF8) and anti-rabbit glucose transporter (GLUT-4, R820) were purchased from East-Acres Biologicals (Southbridge, MA).

Animals and treatment. Male Sprague-Dawley rats weighing 150 $160 \mathrm{~g}$ were used in the studies. Diabetes was induced by a single STZ injection $(65 \mathrm{mg} / \mathrm{kg}$ body wt, i.v. dissolved in $0.01 \mathrm{M}$ citrate buffer, $\mathrm{pH}$ 4.5). Diabetic animals (blood sugar $>400 \mathrm{mg} / \mathrm{dl}$ and plasma insulin $<4 \mu \mathrm{U} / \mathrm{ml}$ ) were subdivided into six groups: ( $a$ ) untreated for $2 \mathrm{~d}$; $(b)$ untreated for $7 \mathrm{~d}$; $(c)$ untreated for $14 \mathrm{~d}$; $(d)$ untreated for $2 \mathrm{~d}$ followed by insulin treatment for $5 \mathrm{~d}$ (daily subcutaneous injections of 5-6 $\mathrm{U}$ $\mathrm{NPH}$ ); (e) untreated for $2 \mathrm{~d}$ followed by vanadate treatment for $5 \mathrm{~d}$ (sodium orthovanadate, $0.2 \mathrm{mg} / \mathrm{ml}$ in drinking water); and $(f)$ untreated for $2 \mathrm{~d}$ followed by phlorizin treatment for $5 \mathrm{~d}(0.49 / \mathrm{kg}$ body wt) prepared as a $40 \%$ solution in propylene glycol and injected SQ every $8 \mathrm{~h}$ to ensure continuous inhibition of renal tubular reabsorption of glucose (15). Insulin therapy normalized blood sugar levels and restored adequate weight gain within $5 \mathrm{~d}$. Vanadate- and phlorizintreated animals became normoglycemic but remained insulinopenic and failed to gain weight (16). All animals had free access to food and water ad lib. Control animals were injected with citrate buffer instead of STZ. Animals were killed by decapitation and epididymal fat pads were removed to ice-cold containers with PBS. At the time of sacrifice, urine was tested for sugar and blood was collected for glucose and insulin determinations.

Preparation of isolated adipocytes. Isolated adipocytes were prepared by collagenase digestion, according to the method of Rodbell (17).

Measurement of 2-deoxyglucose transport. The procedure was described in our previous publications (18). In brief, the cells were incubated with and without insulin (final concentration $25 \mathrm{ng} / \mathrm{ml}$ ) for 30 $\min$ at $37^{\circ} \mathrm{C}$. Glucose transport was initiated by the addition of $50 \mu \mathrm{l}$ of [ $\left.{ }^{3} \mathrm{H}\right] 2$-deoxyglucose $\left(4 \mu \mathrm{Ci}\left[{ }^{1-3} \mathrm{H}\right] 2\right.$-deoxyglucose/ml in $2 \mathrm{mM} 2$-deoxyglucose). At the end of $3 \mathrm{~min}, 300-\mu \mathrm{l}$ aliquots of cell suspension was added to Eppendorf tubes containing silicone oil and the cells were separated from the medium by rapid centrifugation. The cell pellet portion of the tube was cut off and counted in a liquid scintillation counter.

Incubation of adipocytes with $\left[{ }^{32} P\right]_{i}$. Adipocytes prepared from control and diabetic rats were resuspended in low $\mathrm{P}_{\mathrm{i}}$ medium containing the following (mM): $145 \mathrm{NaCl}, 5.4 \mathrm{KCl}, 1.4 \mathrm{CaCl}_{2}, 1.4 \mathrm{MgSO}_{4}, 0.2$ $\mathrm{NaPO}_{4}, 30 \mathrm{mg} / \mathrm{ml} \mathrm{BSA}$, and 10 Hepes ( $\mathrm{pH} \mathrm{7.4)}$ and were incubated at $37^{\circ} \mathrm{C}$ with $\left[{ }^{32} \mathrm{P}\right.$ ] orthophosphate $(0.3 \mathrm{mCi} / \mathrm{ml})$ for $2 \mathrm{~h}$ to achieve steady state labeling of cells with $\left[{ }^{32} \mathrm{P}\right]_{\mathrm{i}}(12,13)$. The ${ }^{32} \mathrm{P}$-labeled cells from control and diabetic rats were subsequently divided into two equal groups, one of which was incubated with insulin ( $100 \mathrm{nM})$ for an additional $30 \mathrm{~min}$. At the end of the incubation, the cells were centrifuged at $800 \mathrm{~g}$ for $15 \mathrm{~s}$ and the medium was aspirated. The cells were rinsed at $37^{\circ} \mathrm{C}$ in HES buffer containing phosphatase and protease inhibitors (13). The cells were immediately homogenized at $0^{\circ} \mathrm{C}$ in HES buffer using a glass homogenizer and a teflon pestle (six strokes) at 1,500 rpm. HES buffer contained the following (mM): 10 Hepes, 255 sucrose, 1 EDTA, 50 sodium fluoride, $200 \mu \mathrm{M}$ sodium orthovanadate, 50 sodium pyrophosphate, $10 \mu \mathrm{g} / \mathrm{ml}$ leupeptin, $10 \mu \mathrm{g} / \mathrm{ml}$ aprotinin, 1 benzamidine, $1 \mathrm{PMSF}$, and $10 \mu \mathrm{g} / \mathrm{ml}$ soya trypsin inhibitor ( $\mathrm{pH}$ 7.4). In some experiments, cells were homogenized in the above buffer containing $1 \%$ SDS to ensure rapid denaturation of proteins and complete extraction of the ${ }^{32}$ P-labeled GLUT-4 $(12,13)$.
Subcellular fractionation of ${ }^{32} P$-labeled adipocytes. The cell homogenates were also used for rapid subcellular fractionation according to the method of James et al. (12). The rapid fractionation procedure reduced the possibility of changes occurring in the phosphorylation state of the glucose transporter during the fractionation. Plasma membrane (PM) and low density microsomal (LDM) fractions were resuspended in homogenization buffer and assayed for protein contents using bicinchoninic acid (13). 5'-nucleotidase activity was measured in the plasma membranes of control and diabetic rats (5'-nucleotidase activity kit; Sigma Chemical Co.). Diabetes did not result in altered distribution of the enzyme marker or the protein contents.

Immunoprecipitation of ${ }^{32} P$-labeled GLUT-4 and electrophoretic analyses. Glucose transporters were immunoprecipitated using the monoclonal antibody IF8 $(12,13)$. SDS-solubilized PM, LDM, and cell homogenates ( $100 \mu \mathrm{l} ; 50-100 \mu \mathrm{g}$ of protein) were added to $900 \mu \mathrm{l}$ of HES buffer containing $1 \%$ Triton X-100, $100 \mathrm{mM} \mathrm{NaCl}$, protease and phosphatase inhibitors. Samples were incubated for $30 \mathrm{~min}$ at $22^{\circ} \mathrm{C}$ and centrifuged for $5 \mathrm{~min}$ at $13,000 \mathrm{~g}$. Supernatants were used for immunoprecipitation with IF8. The monoclonal antibody was first immobilized by incubation at $22^{\circ} \mathrm{C}$ with goat anti-mouse IgG (binding capacity $0.4 \mathrm{mg} \mathrm{IgG/} / \mathrm{ml}$ packed beads) coupled to agarose beads ( $1 \mu \mathrm{g}$ of antimouse IgG/ $1 \mu \mathrm{g}$ of IF8) and was suspended in HES buffer containing $0.1 \%$ BSA. After 60 min of incubation with constant shaking, the beads were pelleted by centrifugation and washed three times with HES buffer containing $1 \%$ Triton X-100, $100 \mathrm{mM} \mathrm{NaCl}$, protease and phosphatase inhibitors. Beads (100-200 $\mu$ l) were then added to solubilized samples and incubation was continued for $60 \mathrm{~min}$ at $22^{\circ} \mathrm{C}$ with constant shaking. The samples were centrifuged at $13,000 \mathrm{~g}$ for $10 \mathrm{~s}$ and the pelleted beads containing immune complexes were washed with HES containing $1 \%$ Triton X-100. SDS sample buffer $(30 \mu \mathrm{l})$ was added to elute glucose transporters. Samples were incubated for $10 \mathrm{~min}$ at $37^{\circ} \mathrm{C}$ before electrophoresis was performed using $10 \%$ SDS-polyacrylamide resolving gels (19). After electrophoresis, gels were dried and exposed to Kodak X-AR 5 film at $-70^{\circ} \mathrm{C} .{ }^{32} \mathrm{P}$ was quantitated by optical density scanning of autoradiograms and the results were compared with the cut and count technique. Low molecular weight standards from Bio-Rad Laboratories were always run with the sample to estimate the molecular weight of the glucose transporters.

Immunoblotting was performed to estimate the relative amounts of transporters in control and diabetic preparations and in different subcellular fractions. Proteins were electrophoretically transferred from SDS gels to nitrocellulose sheets or immunolite membranes supplied by Bio-Rad Laboratories according to the manufacturer's instructions. To identify the GLUT-4 transporter, the membranes were incubated with the polyclonal antibody $\operatorname{R} 820(12,13)$. Antibody binding was detected by chemiluminescence (Bio-Rad Laboratories).

Assay of PSPase activity. PSPase activity present in particulate (PF) and cytosolic fractions (CF) of control and diabetic rat adipocytes was measured according to the method of Shenolikar and Ingebritsen (20), using purified ${ }^{32} \mathrm{P}$-labeled phosphorylase a and ${ }^{32} \mathrm{P}$-labeled GLUT-4 as substrates. PF and CF were prepared from control and diabetic adipocytes according to the method of King and Sale (21). PF and $\mathrm{CF}$ (12-24 $\mu \mathrm{g}$ protein/assay) were preincubated for $2 \mathrm{~min}$ at $30^{\circ} \mathrm{C}$. The reaction was started by the addition of a reaction mixture containing (final concentration) $1 \mathrm{mg} / \mathrm{ml}$ of $\left[{ }^{32} \mathrm{P}\right]$ phosphorylase a, $40 \mathrm{mM}$ Tris-Hcl (pH 7.0), 1 mM EDTA, $20 \mathrm{mM} \beta$-mercaptoethanol in a final volume of $100 \mu \mathrm{l}$. At the end of $10 \mathrm{~min}$, the assay was terminated by the addition of $100 \mu \mathrm{l}$ of $20 \%$ TCA and $10 \mu \mathrm{l}$ of $1 \%$ BSA as a carrier protein. Samples were centrifuged at $12,000 \mathrm{~g}$ for $5 \mathrm{~min}$ and aliquots of the supernatant were added to $4 \mathrm{ml}$ of scintillation fluid and counted.

When ${ }^{32} \mathrm{P}$-labeled GLUT-4 was used as a substrate, purified ${ }^{32} \mathrm{P}$-labeled LDM fractions containing 25,000-30,000 cpm were incubated with PF or CF (12-24 $\mu$ g protein) in a final volume of $100 \mu \mathrm{l}$. The reaction mixture contained $40 \mathrm{mM}$ Tris- $\mathrm{Hcl}, \mathrm{pH} 7.0,1 \mathrm{mM}$ EDTA, 20 $\mathrm{mM} \beta$-mercaptoethanol, and $10 \mu \mathrm{g} / \mathrm{ml}$ aprotinin. After $20 \mathrm{~min}$ of incubation at $30^{\circ} \mathrm{C}$, the reaction was stopped by the addition of HES buffer containing $1 \%$ SDS. The samples were diluted to $1 \mathrm{ml}$ with HES buffer containing protease and phosphatase inhibitors and $1 \%$ Triton 
X-100, and GLUT-4 was immunoprecipitated using IF8 antibody as described above. The immunoprecipitates were subjected to SDSPAGE followed by autoradiography. ${ }^{32} \mathrm{P}$ present in GLUT-4 was quantitated by densitometry. Percent dephosphorylation by PF or CF was calculated by subtracting the radioactivity remaining in GLUT-4 from the ${ }^{32} \mathrm{P}$ present in GLUT-4 incubated with buffer alone. Western blotting of a duplicate gel was used to assess the GLUT-4 content. There was no reduction in GLUT-4 content during the incubation with PSPases. Therefore, the decrease in ${ }^{32} \mathrm{P}$ content of GLUT-4 was due to dephosphorylation by PSPases rather than a reduction in the number of transporters immunoprecipitated.

$\left[{ }^{32} \mathrm{P}\right]$ phosphorylase a was prepared by incubating purified phosphorylase $b$ with phosphorylase kinase, $\gamma\left[{ }^{32} \mathrm{P}\right] \mathrm{ATP}$ and $\mathrm{Mg}^{2+}$ according to the method of Antoniw et al. (22) with the modifications described in reference 20 . The unincorporated $\gamma\left[{ }^{32} \mathrm{P}\right] \mathrm{ATP}$ was removed by passing through a small column of Sephadex G-25 and by overnight dialysis against $10 \mathrm{mM}$ Tris buffer ( $\mathrm{pH} 7.0$ ) containing $1 \mathrm{mM}$ EDTA and $50 \mathrm{mM} \beta$-mercaptoethanol. The substrate contained $1.00 \pm 0.04$ mol of phosphate/subunit and $>98 \%$ of the total counts were precipitated by $20 \%$ TCA. Less than $1 \%\left[{ }^{32} \mathrm{P}\right]_{\mathrm{i}}$ was released from the substrate upon storage over a period of $1 \mathrm{mo}$.

LDM or PM prepared from control rat adipocytes were phosphorylated in vitro with cAMP-dependent protein kinase according to the method of Stewart et al. (23). Briefly, the reaction mixture in a final volume of $200 \mu$ l, containing LDM (100 $\mu \mathrm{g}$ protein $/ 100 \mu \mathrm{l}), 6 \mathrm{mM}$ $\mathrm{MgCl}_{2}, 200 \mu \mathrm{M}$ ATP, $2 \mathrm{U}$ catalytic subunit of protein kinase A, and $200 \mu \mathrm{Ci}$ of $\left.\gamma{ }^{32} \mathrm{P}\right] \mathrm{ATP}$ was incubated for $1 \mathrm{~h}$ at $30^{\circ} \mathrm{C}$. The reaction was terminated by the addition of $100 \mathrm{mM} \mathrm{NaF}$ followed by desalting using a small Sephadex G-25 column. The fraction containing ${ }^{32} \mathrm{P}$-labeled LDM was used for dephosphorylation assays.

Protein assay. The amount of proteins was determined by the method of Bradford (24) or by bicinchoninic acid (13).

Statistics. Student's $t$ test was used to evaluate the significance of the effect of diabetes, insulin, and vanadate treatment on PSPases, GLUT-4 content, and phosphorylation status of GLUT-4. Paired $t$ test was used to evaluate the effect of insulin on the translocation of glucose transporters. The results are presented as mean \pm SEM of four to six individual experiments performed in duplicate.

\section{Results}

Effect of diabetes on insulin stimulated 2-deoxyglucose uptake. Insulin-stimulated glucose transport was significantly reduced $(P<0.001)$ in diabetic rat adipocytes (Fig. 1). The insulinstimulated glucose uptake was decreased by $38 \%$ on the 2 nd day, by $61 \%$ on the 7 th day, and by $63 \%$ on the 14 th day of diabetes. A 40-60\% decrease in glucose uptake was observed at maximally and submaximally effective insulin concentrations (data not shown). Insulin treatment for $5 \mathrm{~d}$ restored glucose uptake to control levels.

Effect of diabetes on the phosphorylation status of GLUT-4. Recent studies from several laboratories $(12,13,25)$ have suggested that phosphorylation of GLUT-4 may modulate its intrinsic activity. Our own observations indicated that high $\left[\mathrm{Ca}^{2+}\right]_{\mathrm{i}}$ enhances phosphorylation of GLUT-4 in isolated rat adipocytes (14). Therefore, we examined the phosphorylation state of GLUT-4 in adipocytes isolated from diabetic animals. To quantitate the magnitude of phosphorylation, the amount of GLUT-4 protein was determined by Western blotting in each experiment. Fig. 2 depicts a representative experiment performed in control, 2- and 14-d diabetic rats. Diabetes resulted in significant $(P<0.05)$ reductions in adipocyte GLUT4 contents ( Fig. 2, $B$ and $D$ ). In contrast to decreased amounts of GLUT-4 protein, we observed a two- to threefold increase in ${ }^{32} \mathrm{P}$ contents of $46-\mathrm{kD}$ protein immunoprecipitated by mono-

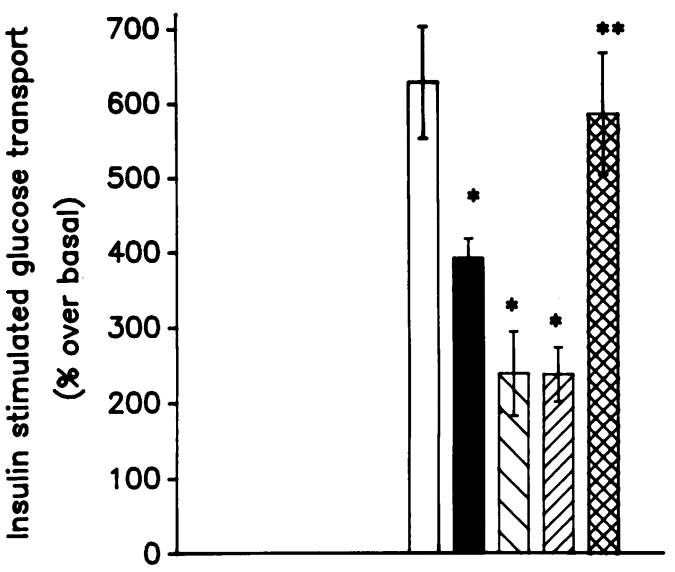

Figure 1. Effect of STZ-induced diabetes on insulin-stimulated 2-deoxyglucose uptake in adipocytes. Adipocytes from control and diabetic rats were incubated with and without insulin $(25 \mathrm{ng} / \mathrm{ml})$ for 30 min at $37^{\circ} \mathrm{C}$. Results are the mean \pm SEM of five to seven independent experiments performed in triplicate. ${ }^{*} P<0.001$ versus controls; ${ }^{* *} P<0.01$ versus untreated diabetics. $\square$, Control; $\bullet, 2$ d diabetes; $\square$, $7 \mathrm{~d}$ diabetes; $14 \mathrm{~d}$ diabetes; $7 \mathrm{~d}$ diabetes + Ins.
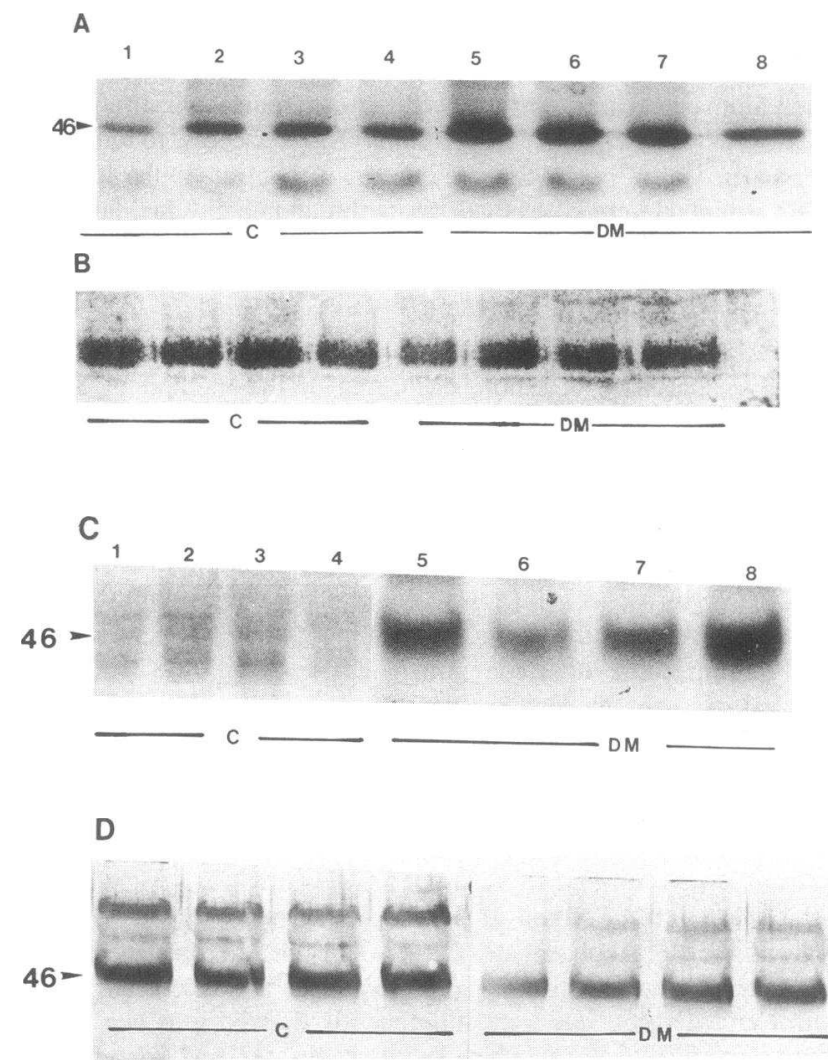

Figure 2. Phosphorylation of GLUT-4 in diabetic rat adipocytes. Autoradiogram from a representative experiment. Adipocytes from control or diabetic rats were incubated with $\left[{ }^{32} \mathrm{P}\right]_{\mathrm{i}}(0.25 \mathrm{mCi} / \mathrm{ml})$ for $2 \mathrm{~h}$. ${ }^{32} \mathrm{P}$-labeled GLUT-4 was immunoprecipitated using mAb IF8. Samples were divided into two equal parts and subjected to SDS-PAGE with a $10 \%$ resolving gel. $A$ and $C$ show autoradiogram of a dried gel showing increased phosphorylation of GLUT-4 in 2 and $14 \mathrm{~d}$ of diabetes, respectively. $B$ and $D$ show detection of GLUT-4 (after transfer of proteins to nitrocellulose) by using the polyclonal antibody ( $R 820)$ and anti-rabbit IgG coupled to alkaline phosphatase in $2(B)$ and 14 $\mathrm{d}(D)$ of diabetes. $(C)$ controls; $(D M)$ diabetic. 
clonal antibody to GLUT-4 (Fig. 2, $A$ and $C$ ). The mobility of the phosphorylated band corresponded exactly with that of the glucose transporter detected by immunoblotting with a polyclonal antibody R820 (Fig. $2 B$ and $D$ ).

The summary of the densitometric analysis of several independent experiments is shown in Figs. 3 and 4. The GLUT-4 protein content in diabetic adipocytes was significantly decreased compared with controls (Fig. 3). Insulin treatment of diabetic rats for $5 \mathrm{~d}$ restored the GLUT-4 contents to control levels (Fig. 3) whereas vanadate and phlorizin were without effect.

There was a two- to fourfold increase in phosphorylation status of GLUT-4 (Fig. 4) after correction for variations in the proteins (i.e., GLUT-4 specific activity). To compare results from different experiments, the specific activity of the transporter in control cell homogenates was assigned a value of 1 and the rest of the data was calculated relative to control values. Insulin therapy restored GLUT-4 phosphorylation to normal whereas $5 \mathrm{~d}$ of vanadate or phlorizin treatment were ineffective (Fig. 4).

Effect of diabetes on the subcellular distribution of phosphorylated glucose transporters. The bulk of the insulin-regulatable glucose transporters (GLUT-4) exists within the intracellular pool $(2,3)$. Insulin stimulates translocation of GLUT-4 from the intracellular pool to the plasma membrane. We examined cellular distribution of GLUT-4 along with its state of phosphorylation in diabetic adipocytes (Fig. 5). Fig. $5 B$ represents the Western blot of the GLUT-4 in LDM and PM fractions of control and diabetic adipocytes. Insulin treatment of control adipocytes in vitro resulted in translocation of GLUT4 from LDM (lanes 1 and 2) to PM (lanes 3 and 4). In contrast, insulin had no effect on translocation of GLUT-4 in diabetic adipocytes (lanes 5-8). Fig. $5 \mathrm{~A}$ demonstrates the degree of phosphorylation of GLUT-4 in LDM and PM of control (lanes 1-4) and diabetic (lanes 5-8) adipocytes incubated with and without insulin. In contrast to control preparations,

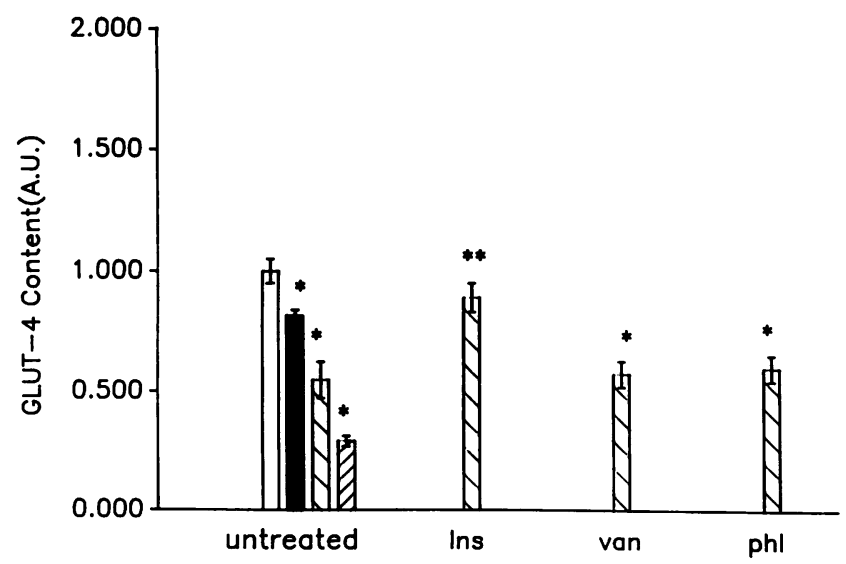

Figure 3. Quantitation of GLUT-4 contents in control and diabetic rats with and without therapy. Western blots from multiple experiments were probed with R820 antibody and anti-rabbit IgG coupled to alkaline phosphatase. The intensity of the signal was quantitated by densitometry. To compare results from different experiments, control GLUT-4 protein content was assigned a value of 1 . Results are expressed as arbitrary densitometric units $(A U) / \mathrm{mg}$ protein. Results are mean \pm SEM of five to six individual experiments performed in duplicate. ${ }^{*} P<0.05$ versus control; ${ }^{* *} P<0.05$ versus untreated diabetic. $\square$, Control; $\mathrm{a}, 2 \mathrm{~d}$ diabetes; $\square, 7 \mathrm{~d}$ diabetes; $\square, 14 \mathrm{~d}$ diabetes.

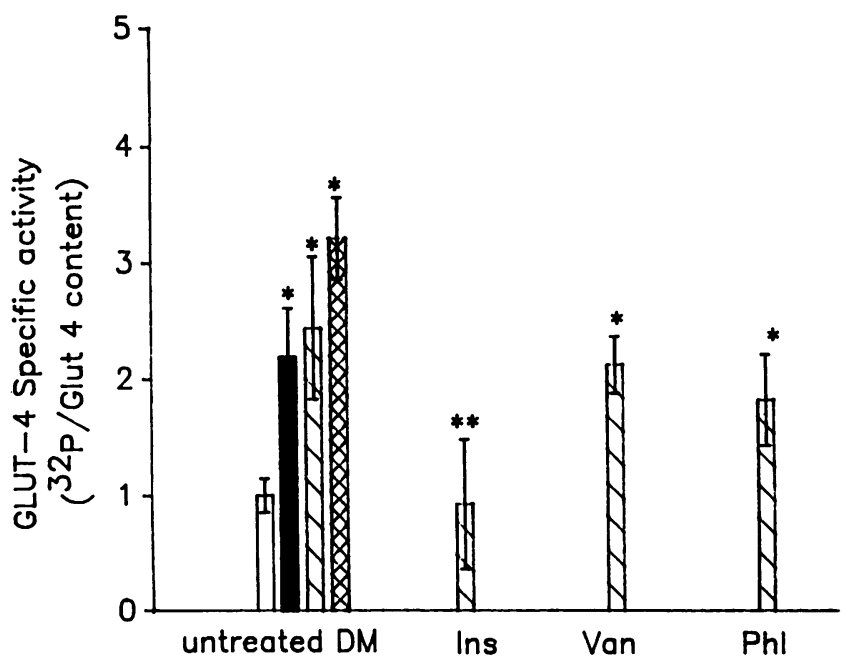

Figure 4. Specific activity of GLUT-4 from multiple experiments. Autoradiograms of ${ }^{32} \mathrm{P}$-labeled GLUT-4 and Western blots of GLUT-4 proteins were scanned for optical density and areas beneath the peaks corresponding to GLUT-4 were determined. Specific activities in arbitrary units (AU) were calculated by dividing the values of ${ }^{32} \mathrm{P}$ peaks by those of protein peaks. To compare results from different experiments, specific activity of controls was assigned a value of 1 . Results are mean \pm SEM of five to six individual experiments performed in duplicate. ${ }^{*} P<0.05$ versus control; ${ }^{* *} P<0.05$ versus untreated diabetic. $\square$, Control; $\backsim, 2 \mathrm{~d}$ diabetes; $\square, 7 \mathrm{~d}$ diabetes; $\square, 14$ $\mathrm{d}$ diabetes.

GLUT-4 from diabetic PM and LDM fractions was heavily phosphorylated in the basal state (Fig. $5 \mathrm{~A}$, lanes 5 and 7) as well as after treatment of adipocytes with insulin (lanes 6 and 8).

Quantitative densitometric analyses of the autoradiograms depicting GLUT-4 content and phosphorylation state are seen in Figs. 6 and 7. There was a significant reduction in the diabetic LDM GLUT-4 content compared with control LDM (Fig. 6). In contrast, diabetic PMs showed a significant increase (45\%) in GLUT-4 content compared with control preparations. Although an exposure of adipocytes to insulin resulted in a five- to sixfold increase in GLUT-4 content in control PM, there was an impaired translocation of GLUT-4 in diabetes. Conceivably, impaired translocation of GLUT-4 in diabetes may be related to a high basal PM GLUT-4 content.

In control adipocytes, insulin significantly decreased phosphorylation of GLUT-4 both in the PM and LDM fractions ( $P$ $<0.05$, Fig. 7). To confirm these observations, we analyzed the effect of insulin on GLUT-4 content and phosphorylation in the total cell homogenate. ${ }^{32} \mathrm{P}$-labeled control adipocytes were used in these experiments. Western blotting revealed identical total cell lysate GLUT-4 in the insulin-treated and untreated cells. In contrast, GLUT-4 phosphorylation was significantly reduced in the insulin-treated cells (data not shown). These observations suggest that exposure of adipocytes to insulin results not only in translocation of GLUT-4 from LDM to PM, but also in significant dephosphorylation of GLUT-4. Diabetic preparations showed a twofold increase in the specific activity of GLUT-4, both in LDM and PM fractions. Acute in vitro insulin treatment of diabetic adipocytes did not alter the phosphorylation state of GLUT-4.

At this point, we performed additional experiments to confirm that the 46-kD phosphorylated band was indeed GLUT-4. 

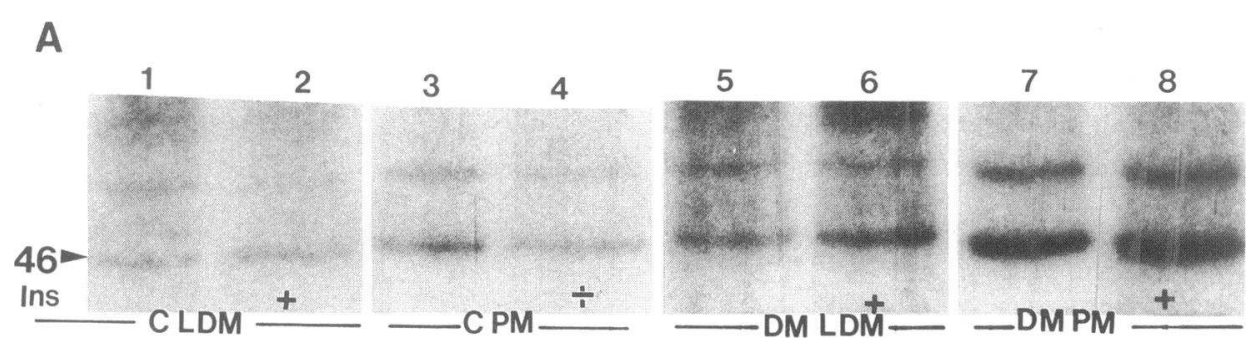

B

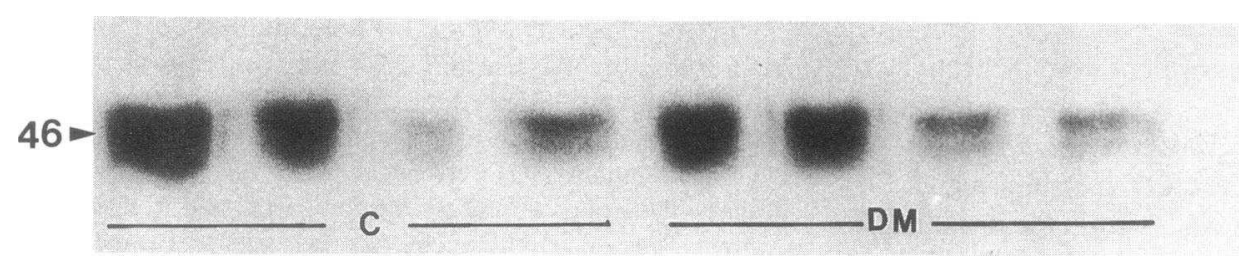

Figure 5. Effect of diabetes on GLUT-4 phosphorylation and GLUT-4 protein distribution in subcellular fractions. Adipocytes were labeled with $\left[{ }^{32} \mathrm{P}\right]_{\mathrm{i}}(0.25 \mathrm{mCi} /$ $\mathrm{ml}$ ) for $2 \mathrm{~h}$ and incubated with insulin ( $100 \mathrm{nM})$ for $30 \mathrm{~min}$. Subcellular fractionation was performed to obtain LDM and PM. The ${ }^{32} \mathrm{P}$-labeled GLUT-4 was immunoprecipitated from each fraction as described in Fig. 2. Samples were divided into two parts and subjected to SDSPAGE autoradiography and Western blotting. $(A)$ Autoradiogram of a dried gel. $(B)$ Western blot of the immunoprecipitated GLUT-4 after detection with R820 and antimouse IgG coupled to alkaline phosphatase. Bands were visualized using chemiluminescent substrate. ( $C L D M$, control LDM; CPM, control PM; $D L D M$, diabetic LDM; $D M P M$, diabetic PM). Autoradiogram from a representative experiment.
Adipocytes isolated from control and 2-d diabetic rats were equilibrated with ${ }^{32} \mathrm{P}$ as described in Methods. Cell lysates were immunoprecipitated with monoclonal antibody to GLUT-4 (IF8) or with preimmune serum. The immunoprecipitates were separated on $10 \%$ SDS-polyacrylamide gel. Proteins corresponding to molecular mass $46 \mathrm{kD}$ were cut out from the gel and electroeluted using Isco (Lincoln, NE) electrophoretic protein concentrator. The eluted proteins were divided into two parts and again subjected to $10 \%$ SDS-polyacrylamide gel electrophoresis. One gel was transferred to immunolite membrane, reblotted with polyclonal antibody (RaIRGT), and GLUT-4 was detected by the chemiluminescent technique. The second gel was used for autoradiography. The Western blot analysis of the eluted proteins demonstrated a single 46$\mathrm{kD}$ band (Fig. $8 A$ ). There was no signal when the preimmune

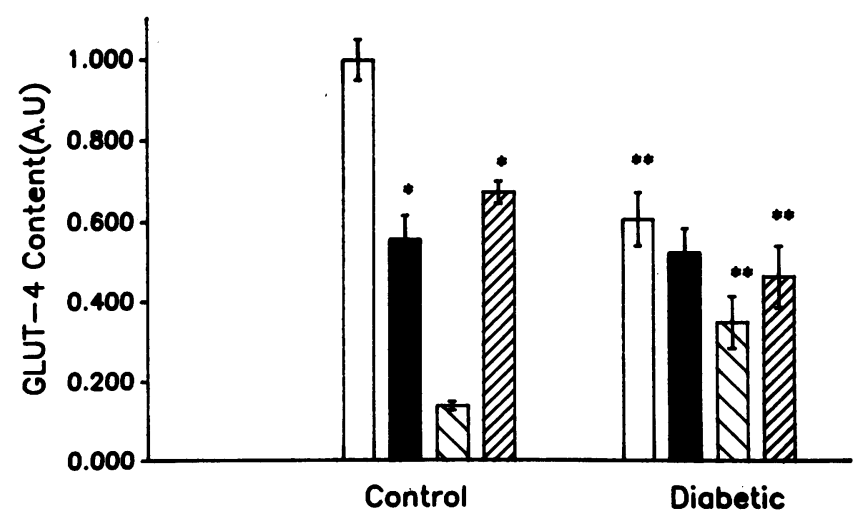

Figure 6. Quantitation of GLUT-4 contents in various subcellular fractions. Results are the mean \pm SEM of five individual experiments. To compare different experiments, GLUT-4 content of control LDM was assigned a value of 1 and the rest of the data was calculated relative to control LDM. ${ }^{*} P<0.05$ versus insulin ireatment; ${ }^{* *} P<0.05$ versus control. $\square, \mathrm{LDM}$; $\sqsubset$, insulin tx LDM; $\square, \mathrm{PM} ; \approx$, insulin tx PM. serum instead of IF8 was used for immunoprecipitation (lane 1). Lane 2 shows the presence of GLUT- 4 in the eluted sample from the control cells and lane 3 demonstrates GLUT-4 protein eluted from the immunoprecipitates of diabetic cell lysates. The content of GLUT- 4 in diabetic adipocytes was signifcantly less compared with control preparations. Fig. $8 B$ is the autoradiogram of the duplicate gel demonstrating increased phosphorylation of GLUT-4 in diabetic preparations. These results confirm the specificity of immunoprecipitation and the identity of GLUT-4.

The site of GLUT-4 phosphorylation in diabetes remains unknown. Lawrence et al. (26) have previously identified the site of GLUT-4 phosphorylation with isoproterenol, a cyclic AMP (cAMP) agonist. To test indirectly if the phosphorylation of GLUT-4 in diabetes involves the same site, we attempted to phosphorylate LDM and PM GLUT-4 isolated from diabetic

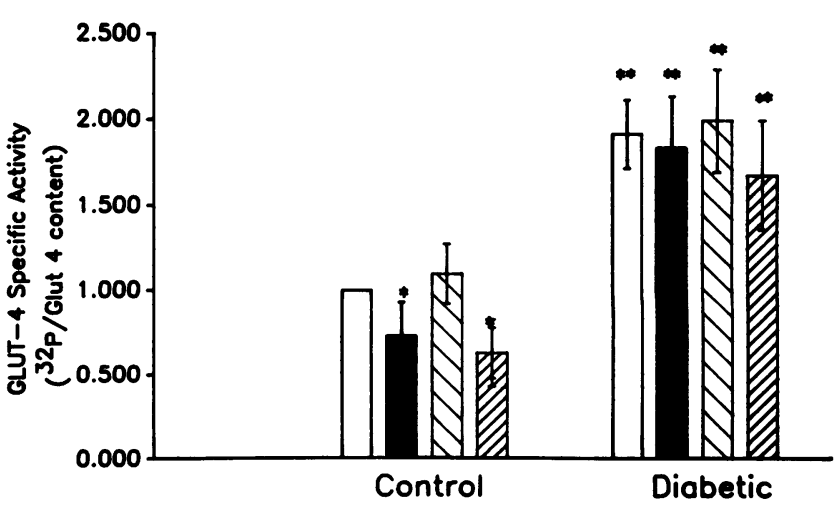

Figure 7. Specific activity of GLUT-4 in subcellular fractions. Details are given in Figs. 4, 5, and 6. Results are the mean \pm SEM of five individual experiments performed in duplicate. ${ }^{*} P<0.05$ versus no insulin treatment; ${ }^{* *} P<0.05$ versus control. $\square, \mathrm{LDM} ; \mathrm{a}$, insulin $\mathrm{tx}$ LDM; $\square$, PM; , insulin tx PM. 

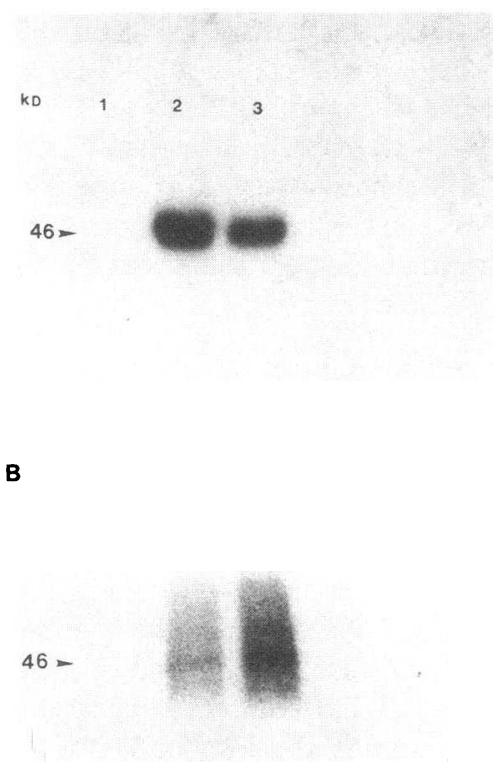

Figure 8. Specificity of the immunoprecipitation of GLUT-4. ${ }^{32} \mathrm{P}-\mathrm{la}$ beled cell lysates $(1 \mathrm{mg}$ protein) from control and 2-d diabetic rat adipocytes were treated with preimmune serum or mAb-IF8 coupled to anti-mouse IgG agarose. The immunoprecipitates were separated by $10 \%$ SDS-PAGE.

The proteins corresponding to molecular mass $46 \mathrm{kD}$ were cut, electroeluted, divided into two aliquots, and subjected to $10 \%$ SDSPAGE. The gels were used for Western blotting with polyclonal GLUT-4 antibody or autoradiography. $(A)$ Western blot analysis of the IF8 immunoprecipitated, eluted $46-\mathrm{kD}$ protein from control and diabetic adipose cell lysates (lanes 2 and 3, respectively). Lane 1 , proteins eluted from the immunoprecipitates using preimmune serum. ( $B$ ) Autoradiogram of the duplicate gel, showing GLUT-4 phosphorylation. Lane order as in $A$.

adipocytes in vitro with cAMP-dependent protein kinase. In contrast to control preparations, diabetic LDMs and PMs showed only minimal incorporation of ${ }^{32} \mathrm{P}$ in GLUT-4 (data not shown), suggesting that glucose transporters in diabetic adipocytes were already phosphorylated in vivo by cAMP-dependent mechanisms.

Effect of diabetes on GLUT-4 dephosphorylation by PSPases. The state of phosphorylation of GLUT-4 reflects a balance between the activities of kinases that phosphorylate and the activities of phosphatases which dephosphorylate this protein. Studies by Lawrence et al. (13) have shown that GLUT-4 could be dephosphorylated by PP-1 and PP-2A with equal affinities and okadaic acid, a potent phosphatase inhibitor, causes an increase in GLUT-4 phosphorylation.

To investigate the mechanism of the increase in the phosphorylation of GLUT-4 in diabetes, we assessed phosphatase activity in diabetic adipocytes. The in vitro ${ }^{32} \mathrm{P}$-labeled LDM fraction from control adipocytes was used as substrate to assay PSPase activity present in the PF and CF of control and diabetic rat adipocytes. At the end of dephosphorylation reaction, the GLUT-4 was immunoprecipitated and analyzed by SDSPAGE and autoradiography. The ${ }^{32} \mathrm{P}$ content of GLUT-4 before and after treatment with PP-1 was quantitated by densitometric scanning. In a separate experiment, we observed that in normal adipocytes $52 \%$ of the phosphatase activity was associated with particulate fractions and $48 \%$ with the cytosolic fractions. Fig. 9 shows the representative autoradiogram of the immunoprecipitated GLUT-4 (Fig. $9 A$ ) and densitometric analysis of the ${ }^{32}$ P-GLUT-4 specific activity after dephosphorylation by PSPases ( Fig. $9 \mathrm{~B}$ ). There was an apparent redistribution of PSPases activity in diabetes. At 2 and $7 \mathrm{~d}$ of diabetes, we found an increase in particulate PSPase activity (lanes 2 vs. 3 and 6 vs. 7) and a corresponding decrease in cytosolic PSPase activity (lanes 4 vs. 5 and 9 vs. 10). Quantitative analysis demonstrated that particulate PSPases from diabetic rat adipocytes dephosphorylated GLUT -4 by $30 \pm 8 \%$ whereas PSPases from control preparations caused only $19 \pm 3.6 \%$ dephosphorylation. Similar results were obtained when the GLUT-4 immunoprecipitated from control LDM was used as a substrate (not shown). Hence, diabetes resulted in a 50-65\% increase in particulate PSPase activity. In contrast, cytosolic fractions from diabetic rats (either 2- or 7-d duration) showed a significant inhibition of PSPase activity (decreased dephosphorylation of GLUT-4). The loss of phosphatase activity in the cytosolic compartment was totally recovered in the particulate fraction, suggesting altered distribution of the PSPase between the two compartments (Fig. $9 \mathrm{~B}$ ). Insulin treatment restored the phosphatase activity to control levels in both compartments (Fig. 9 $A$, lanes 8 and 11 , and Fig. $9 B$ ). Alterations in PSPase activity in diabetes were also confirmed using ${ }^{32} \mathrm{P}$-labeled phosphorylase a as a substrate of PSPase (Table I). Diabetes was associated with altered distribution of the enzyme between the par-
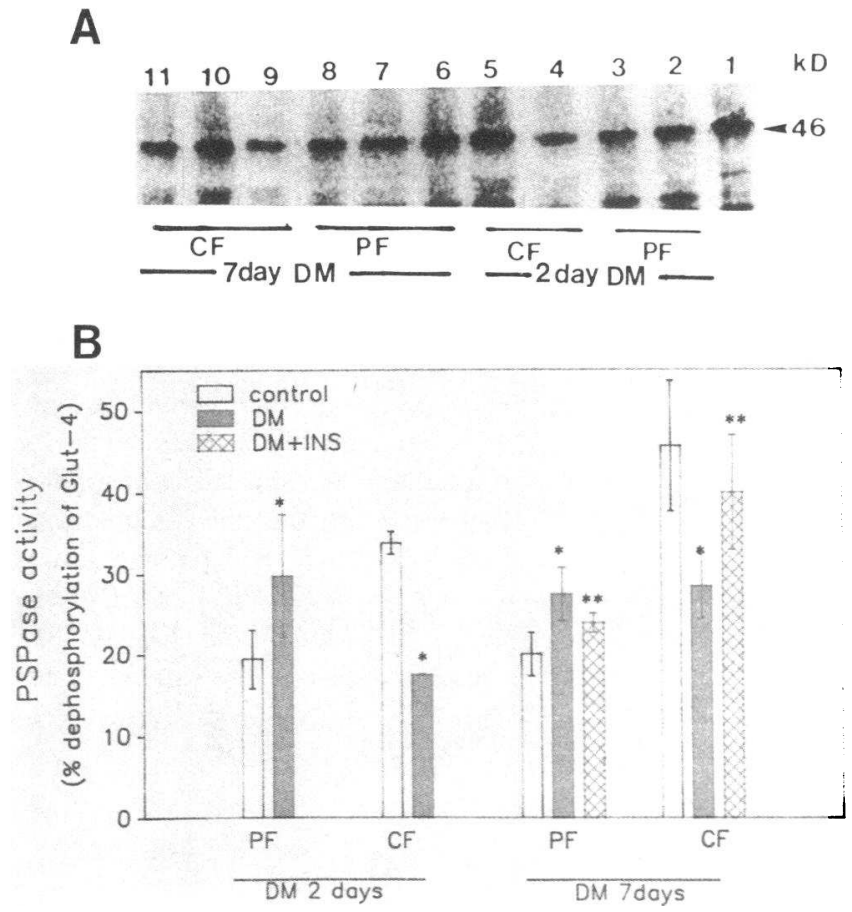

Figure 9. Dephosphorylation of GLUT-4 by PSPases from diabetic rat adipocytes. [ $\left.{ }^{32} \mathrm{P}\right]$ LDM prepared from control adipocytes were used as substrate to assay PSPase activity present in the particulate fraction $(P F)$ and cytosolic fraction $(C F)$ of diabetic rat adipocytes as detailed in the text. The ${ }^{32} \mathrm{P}-$ GLUT-4 was immunoprecipitated from the LDMs after dephosphorylation reaction using mAb IF8. $(A)$ Autoradiogram from a representative experiment. Lane $1,{ }^{32} \mathrm{P}$-labeled GLUT-4 incubated in the presence of buffer alone; lane 2, control PF; lane 3, 2-d diabetic PF; lane 4, control CF; lane 5, 2-d diabetic CF; lane 6, 7-d control PF; lane 7, 7-d diabetic PF; lane 8, 7-d DM + INS; lane 9, 7-d control CF; lane 10,7-d DM CF; and lane 11,7-d DM + INS CF. ( $B$ ) Quantitation of the PSPase activity from multiple experiments by densitometry. Activity is expressed as percentage dephosphorylation of GLUT-4. Results are the mean \pm SEM of five individual experiments performed in duplicate. ${ }^{*} P<0.05$ versus control; ${ }^{* *} P<0.05$ versus untreated diabetic. 
Table I. Dephosphorylation of $\left[^{32}\right.$ P]Phosphorylase a by PSPases from Control and Diabetic Rat Adipocytes

\begin{tabular}{llc}
\hline & \multicolumn{2}{c}{ PSPase activity } \\
\cline { 2 - 3 } Treatment & \multicolumn{1}{c}{ PF } & \multicolumn{1}{c}{ CF } \\
\hline & \multicolumn{1}{c}{$n$ mol of substrate hydrolyzed/mg prot per min } \\
None (controls) & $0.675 \pm 0.068$ & $0.544 \pm 0.034$ \\
DM (2-d) & $0.896 \pm 0.093^{*}$ & $0.406 \pm 0.045^{*}$ \\
Control (7-d) & $0.717 \pm 0.176$ & $0.514 \pm 0.076$ \\
DM (7-d) & $0.974 \pm 0.096^{*}$ & $0.360 \pm 0.070^{*}$
\end{tabular}

Details of the assay are described in the text. Results are the mean \pm SEM of three individual experiments performed in duplicate. $\mathrm{PF}$, particulate fraction; $\mathrm{CF}$, cytosolic fraction. ${ }^{*} P<0.05$ versus controls.

ticulate and cytosolic compartments. Treatment with insulin restored PSPase activity to control values.

A decrease in cytosolic PSPase activity in diabetes may explain the greater phosphorylation of GLUT-4 in diabetic LDM. A seemingly paradoxical situation was observed in the particulate fraction where PSPase activity was increased along with increased phosphorylation of PM GLUT-4. This could have resulted from either alterations in the enzyme ("diabetic" PM PSPase) or in the substrate ("diabetic" PM GLUT-4). Since the activity of the diabetic PSPase appears to be increased when tested against control LDM GLUT-4 (Fig. 9), phosphorylase a (Table I), and glycogen synthase (16), it is likely that alterations in the substrate (diabetic PM GLUT-4) interfere with its normal dephosphorylation. To test this possibility, we used $\left.{ }^{32} \mathrm{P}\right]$ GLUT-4 prepared from control and diabetic PM as substrates of diabetic particulate PSPases (Fig. 10). As expected, diabetic enzyme demonstrated much greater activity towards control PM GLUT-4 than control enzyme $(P<0.01)$. Neither control nor diabetic enzyme was able to dephosphorylate "diabetic" PM GLUT-4, suggesting that the glucose transporters present in the plasma membranes of diabetic adipocytes were unable to interact with the enzyme. It is of interest to note that although unable to dephosphorylate diabetic PM GLUT-4, the diabetic particulate PSPases were capable of de-

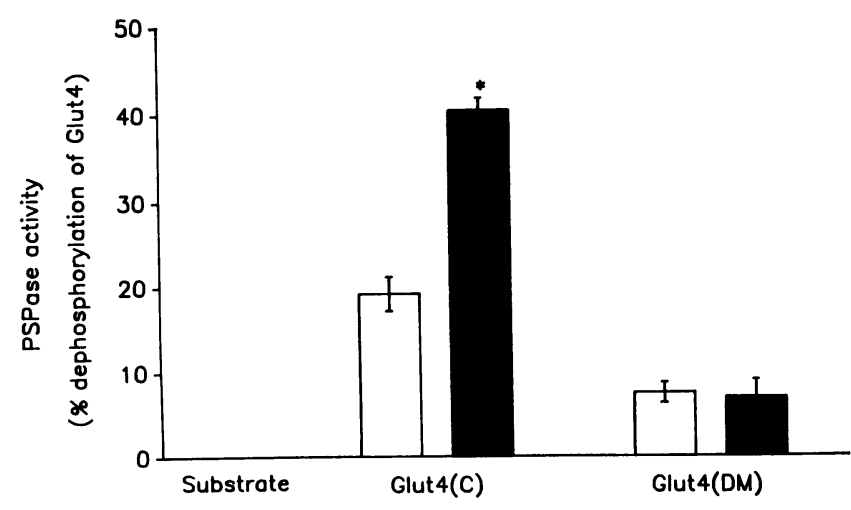

Figure 10. Dephosphorylation of $\left[{ }^{32} \mathrm{P}\right]$ GLUT-4 prepared from control and diabetic plasma membranes by PSPases from control and diabetic adipocytes. Details are given in Fig. 9. Results are the mean \pm SEM of four identical experiments performed in duplicate. ${ }^{*} P$ $<0.05$ versus control. $\square$, Control enzyme; $\mathbf{a}$, DM enzyme. phosphorylating the diabetic LDM GLUT-4 (data not shown), indicating that diabetic GLUT-4 becomes resistant to the PM PSPases after being translocated to the plasma membranes. Alternatively, the phosphorylated sites in diabetic PM GLUT4 may not be accessible to PSPases. This observation was further confirmed in experiments with purified PP-1 (Table II). Purified skeletal muscle PP-1 (a gift from Dr. Shenolikar, Duke University, Durham, NC) dephosphorylated control PM GLUT- 4 by $50-60 \%$ in 15 min. In contrast, when diabetic PM GLUT-4 was used as a substrate, the very same enzyme dephosphorylated it only by $18-20 \%(P<0.05)$.

\section{Discussion}

Four salient observations were made in the course of this study. First, we found significantly increased phosphorylation of GLUT-4 in diabetes (Figs. 2, 4, 5, and 8). This was observed in contrast to a profound decrease in the GLUT-4 content. Enhanced phosphorylation of GLUT-4 was evident both in the PM and LDM fractions. Second, insulin promoted dephosphorylation of GLUT-4 in control, but not in diabetic adipocytes. This modest, but significant dephosphorylation of GLUT-4 by insulin was seen in both subcellular compartments, LDM and PM (Figs. 5 and 7). Third, diabetes resulted in redistribution of PSPase activity, with a loss of such activity in the cytosol and an increase in the particulate fraction. This phenomenon was apparent when PSPase activity was tested with GLUT-4 or phosphorylase a as substrates (Fig. 9, Table I). Finally, inability of highly active diabetic particulate PSPases to dephosphorylate diabetic PM GLUT-4 could be attributed to alterations in diabetic GLUT-4 itself (Fig. 10). These observations taken together with the previous findings of substrate specificity for PSPases (27) indicate great complexity of the dephosphorylation system.

Regulation of GLUT-4 phosphorylation in diabetes. The present study clearly indicates that insulinopenic STZ-induced diabetes results in increased phosphorylation of GLUT-4 despite significant reductions in GLUT-4 protein contents. Treatment of diabetic animals with insulin, but not vanadate or phlorizin, restored GLUT-4 protein contents and reduced its phosphorylation to control levels. Previous studies have demonstrated that vanadate restored phosphotyrosine phosphatase $(16,28)$ and PSPase $(16)$ activities in diabetes after 30 $\mathrm{d}$ of therapy. The lack of phlorizin effect on GLUT-4 content was similar to that observed by Kahn et al. (29). These authors suggested that phlorizin after 10-14 d of administration may have increased glucose transporter intrinsic activity. The differences in the length of treatment do not allow us to directly

Table II. Dephosphorylation of $\left[^{32} P\right] G L U T-4$ Isolated from Plasma Membranes of Control and Diabetic Rat Adipocytes by Purified Skeletal Muscle PP-1

\begin{tabular}{cc}
\hline Substrate & PP-1 activity \\
\hline Control PM ${ }^{32}$ P-GLUT-4 & $57.6 \pm 10.2$ \\
Diabetic PM ${ }^{32}$ P-GLUT-4 & $18.4 \pm 3.1^{*}$
\end{tabular}

Dephosphorylation reaction was carried out with $5 \mu \mathrm{l}$ of 1:100 diluted enzyme in a final volume of $100 \mu \mathrm{l}\left(15 \mathrm{~min}\right.$ at $\left.30^{\circ} \mathrm{C}\right)$. Results are the mean \pm SEM of two individual experiments performed in duplicate. ${ }^{*} P<0.05$. 
compare the present results with those in the literature. Our study demonstrates that after $5 \mathrm{~d}$ of therapy neither vanadate nor phlorizin restored GLUT-4 protein content or its phosphorylation. These observations indicate that insulin may play an important role in the regulation of GLUT-4 phosphorylation. An increase in GLUT-4 phosphorylation together with reductions in GLUT-4 protein content might be responsible for the observed reductions in glucose transport activity in diabetes.

Diabetes is known to be associated with elevations in counterregulatory hormones that elevate cAMP levels (30). The elevated cAMP levels might be responsible for the observed increase in GLUT-4 phosphorylation. Recent studies by James et al. (12) have shown that cAMP agonists (which inhibit insulin-stimulated glucose transport) stimulate GLUT-4 phosphorylation and thereby might modulate the ability of transporters to transport glucose. Okadaic acid, a potent inhibitor of protein phosphatase 1 and 2A also increases GLUT-4 phosphorylation and interferes with the ability of insulin to stimulate glucose uptake $(13,25,31)$.

Our results suggest that insulin promotes dephosphorylation of GLUT-4 during its translocation from the intracellular pool to the PM. In diabetes, GLUT-4 protein of LDM and PM appears to be heavily phosphorylated both in the basal state and after incubation of adipocytes with insulin (Figs. 5, $A$ and 7 ). In contrast to the lack of acute effects of insulin in vitro, $5 \mathrm{~d}$ of insulin therapy restored phosphorylation of GLUT-4 to control levels. Whether the increased phosphorylation of GLUT-4 contributes to the observed impairment in insulin's ability to stimulate glucose uptake in diabetes remains unknown. The state of phosphorylation of GLUT-4 may affect either intrinsic activity of glucose transporter or its cellular translocation (12, 13). Diabetes is known to be accompanied by defective translocation of glucose transporters from the intracellular pool to the PM (4). The relationship of this defect to the state of phosphorylation of GLUT-4 must be explored in the future. Phosphorylation of GLUT-4 has been suggested to alter its cellular distribution $(13,25)$. Recent studies by Lawrence et al. (13) and others (25) suggested that the okadaic acid-induced inhibition of translocation of GLUT-4 is due to increased reinternalization of GLUT-4 in a phosphorylated form. Studies by Corvera and Czech (32) and others $(33,34)$ showed that the insulin-like growth factor II (IGF II) receptor is translocated to the plasma membrane in response to insulin. Moreover, insulin causes a decrease in IGF II receptor phosphorylation in the plasma membranes. These authors showed that insulin-induced phosphorylation of IGF II receptors slowed their rate of internalization and proposed that insulin regulates the cellular location of IGF II receptors by affecting their phosphorylation state. A similar phenomenon may exist for GLUT-4.

Possible mechanisms of diabetes-induced elevations in GLUT-4 phosphorylation. The phosphorylation state of GLUT-4 represents a balance between the activities of kinases and phosphatases. An insulin-deficient state with predominance of cAMP-dependent activation can certainly increase GLUT-4 phosphorylation. On the other hand, an impaired dephosphorylation process may also maintain GLUT-4 in the phosphorylated state. GLUT-4 is phosphorylated on serine residues (26), and both elevated levels of $\left[\mathrm{Ca}^{2+}\right]_{i}$ and cAMP have been previously shown to inhibit adipocyte PSPase activity (35). Our recent observations indicate that the activity of the cytosolic PSPase was inhibited in diabetes, when it was tested with glycogen synthase as a substrate (16). Therefore, to fur- ther investigate the mechanism of the observed increase in phosphorylation of GLUT-4 in diabetes, we assessed PSPase activity using GLUT-4 and phosphorylase a as substrates. Diabetes was associated with reductions in the cytosolic PSPase and elevations in the particulate PSPase activity. Since we measured the total PSPase activity, we cannot rule out the contribution of individual PSPase to this phenomenon. Previous studies (16) indicate that both PP-1 and PP-2A contributed to the increased PSPase activity in diabetes. Low concentrations of okadaic acid (10 $\mathrm{nM})$ inhibited PSPase activity in diabetic adipocytes by $\sim 50 \%$ (PP-2A) whereas at $1 \mu \mathrm{M}$ concentration, it completely inhibited PSPase activity. These findings suggested that the increase in particulate PSPase activity in diabetes was due to elevations in both PP-1 and PP-2A. These changes do not represent alterations in the enzyme's specificity toward a substrate, because identical results were obtained with GLUT-4, phosphorylase a, and glycogen synthase (16). We have previously shown (16) that an inhibition of cytosolic PSPase activity in diabetes cannot be reversed with dilution or with mild trypsinization, ruling out a significant contribution of an inhibitor 1 (16). The data support the notion of redistribution of PSPase in diabetes from the cytosolic to the particulate compartment. Essentially all enzyme activity lost from the cytosol was recovered in the particulate fraction. This suggestion is supported by the recent findings of Clari et al. (36) who demonstrated that an intracellular acidification favored a translocation of tyrosine kinases from the cytosol to the plasma membranes. It is conceivable that alterations in the intracellular $\mathrm{pH}$ in diabetes also promote PSPase translocation.

A decrease in the cytosolic PSPase activity in diabetes correlates well with the observed increase in GLUT-4 phosphorylation in the diabetic LDM preparation. A paradoxical situation was observed in the diabetic particulate fraction. Membranous PSPase activity was increased along with increased phosphorylation of GLUT-4 in the plasma membranes. Experiments using GLUT-4 (prepared from adipocyte plasma membranes of diabetic rats) as a substrate (Fig. 10) revealed that diabetic PM glucose transporters failed to interact with the enzyme. In fact, [ $\left.{ }^{32} \mathrm{P}\right]-G L U T-4$ from diabetic plasma membranes was also poorly dephosphorylated by control PSPases and by the purified skeletal muscle PP-1. It is conceivable that phosphorylation of GLUT-4 in diabetes involves alternate sites which are unaccessible for the action of PSPase.

In summary, we have shown that insulin-deficient diabetes results in increased GLUT-4 phosphorylation most likely via cAMP-mediated processes. Both enhanced kinase activity and diminished phosphatase activity may be responsible for shifting the balance in favor of phosphorylation. Greater phosphorylation may render GLUT-4 less sensitive to acute regulation by insulin.

\section{Acknowledgments}

The authors are extremely grateful to Dr. Kim Heidenreich for her excellent suggestions. The authors gratefully acknowledge the secretarial assistance of Ms. Gloria Smith.

This work was supported by the Veterans Affairs Research Service and by the Diabetes Research Foundation of Colorado.

\section{References}

1. Simpson, I. A., and S. W. Cushman. 1988. Hormonal regulation of mammalian glucose transport. Annu. Rev. Biochem. 55:1059-1089.

2. Cushman, S. W., and L. J. Wardzala. 1980. Potential mechanism of insulin 
action on glucose transport in the isolated rat adipose cell: apparent translocation of intracellular transport systems to the plasma membrane. J. Biol. Chem. 255:4758-4762.

3. Suzuki, K., and T. Kono. 1980. Evidence that insulin causes translocation of glucose transport activity to the plasma membrane from an intracellular storage site. Proc. Natl. Acad. Sci. USA. 77:2542-2545.

4. Karnieli, E., P. J. Hissin, I. H. Simpson, L. B. Salans, and S. W. Cushman. 1981. A possible mechanism of insulin resistance in the rat adipose cell in streptozotocin-induced diabetes mellitus: depletion of intracellular glucose transport system. J. Clin. Invest. 68:811-814.

5. Kahn, B. B., M. J. Charron, H. F. Lodish, S. W. Cushman, and J. S. Flier. 1989. Differential regulation of two glucose transporters in adipose cells from diabetic and insulin-treated diabetic rats. J. Clin. Invest. 84:404-411.

6. Berger, J., C. Biswas, P. P. Bicano, H. V. Strout, R. Saperstein, and P. F. Pilch. 1989. Decreased expression of the insulin-responsive glucose transporter in diabetes and fasting. Nature (Lond.). 340:70-72.

7. Garvey, W. T., T. P. Huecksteadt, S. Mathaei, and J. M. Olefsky. 1988. The role of glucose transporters in the cellular insulin resistance of Type II non-insulin-dependent diabetes mellitus. J. Clin. Invest. 81:1528-1536.

8. Sinha, M. K., C. L. Maldonado, C. Buchanan, W. J. Pories, C. C. Su, P. F. Pilch, and J. F. Caro. 1991. Adipose tissue glucose transports in NIDDM. Decreased levels of muscle/fat isoform. Diabetes. 40:472-477.

9. Kahn, B. B., and S. W. Cushman. 1987. Mechanism for markedly hyper-responsive insulin-stimulated glucose transport activity in adipose cells from insulin-treated streptozotocin diabetic rats: evidence for increased glucose transporter intrinsic activity. J. Biol. Chem. 262:5118-5124.

10. Karnieli, E., M. Armoni, P. Cohen, Y. Kanter, and R. Rafaeloff. 1987. Reversal of insulin resistance in diabetic rat adipocytes by insulin therapy. Restoration of pool of glucose transporters and enhancement of glucose transport activity. Diabetes. 36:925-931.

11. Gibbs, E. M., W. J. Allard, and G. E. Leinhard. 1986. The glucose transporter in 3T3-Ll adipocytes is phosphorylated in response to phorbol ester but not in response to insulin. J. Biol. Chem. 261:16597-16603.

12. James, D. E., J. Hiken, and J. C. Lawrence, Jr. 1989. Isoproterenol stimulates phosphorylation of the insulin-regulatable glucose transporter in rat adipocytes. Proc. Natl. Acad. Sci. USA. 86:8368-8372.

13. Lawrence, Jr., J. C., J. F. Hiken, and D. E. James. 1990. Stimulation of glucose transport and glucose transporter phosphorylation by okadaic acid in rat adipocytes. J. Biol. Chem. 265:19768-19776.

14. Reusch, J. E.-B., N. Begum, K. E. Sussman, and B. Draznin. 1991. Regulation of GLUT 4 phosphorylation by intracellular calcium in adipocytes. Endocrinology. 129:3269-3273.

15. Rosetti, L., D. Smith, G. I. Schulman, D. Papachristou, and R. A. DeFronzo. 1987. Correction of hyperglycemia with phlorizin normalizes tissue sensitivity to insulin in diabetic rats. J. Clin. Invest. 79:1510-1515.

16. Begum, N., K. E. Sussman, and B. Draznin. 1991. Differential effects of diabetes on adipocyte and liver phosphotyrosine and phosphoserine phosphatase activities. Diabetes. 40:1620-1629.

17. Rodbell, M. 1964. Metabolism of isolated fat cells. J. Biol. Chem 239:375-380.

18. Draznin, B., D. Lewis, N. Houlder, N. Sherman, M. Adamo, T. W. Garvey, D. LeRoith, and K. E. Sussman. 1989. Mechanism of insulin resistance induced by sustained levels of free cytosolic calcium in rat adipocytes. Endocrinology. 125:2341-2349.

19. Laemmli, U. K. 1970. Cleavage of structural proteins during the assembly of the head of bacteriophage T4. Nature (Lond.). 227:680-685.
20. Shenolikar, S., and T. S. Ingebritsen. 1984. Protein (serine and threonine) phosphate phosphatases. Methods Enzymol. 107:102-129.

21. King, M. J., and G. J. Sale. 1990. Dephosphorylation of insulin receptor autophosphorylation sites by particulate and soluble phosphotyrosyl protein phosphatases. Biochem. J. 266:251-259.

22. Antoniw, J. F., H. G. Nimmo, S. J. Yeaman, and P. Cohen. 1977. Comparison of the substrate specificities of protein phosphatase involved in the regulation of glycogen metabolism in rabbit skeletal muscle. Biochem. J. 162:423-433.

23. Stewart, A. A., B. A. Hemmings, P. Cohen, J. Grosis, and W. Merlevada. 1981. The Mg-ATP dependent protein phosphatase and phosphatase 1 have identical substrate specificities. Eur. J. Biochem. 115:197-205.

24. Bradford, M. M. 1976. A rapid and sensitive method for the quantitation of microgram quantities of proteins utilizing the principle of protein-dye binding. Anal. Biochem. 72:248-254.

25. Corvera, S., S. Jaspers, and M. Pasceri. 1991. Acute inhibition of insulinstimulated glucose transport by the phosphatase inhibitor-okadaic acid. J. Biol. Chem. 266:9271-9275.

26. Lawrence, Jr., J. C., J. F. Hiken, and D. E. James. 1990. Phosphorylation of the glucose transporter in rat adipocytes. Identification of the intracellular domain at the carboxyl terminus as a target for phosphorylation in intact cells and in vitro. J. Biol. Chem. 265:2324-2332.

27. Cohen, P., and P. T. W. Cohen. 1989. Protein phosphatases come of age. J. Biol. Chem. 264:21435-21438.

28. Meyerovitch, J., J. M. Backer, and C. R. Kahn. 1989. Hepatic phosphotyrosine phosphatase activity and its alteration in diabetic rats. J. Clin. Invest. 84:976-983.

29. Kahn, B. B., G. I. Shulman, R. A. DeFronzo, S. W. Cushman, and L. Rossetti. 1991. Normalization of blood glucose in diabetic rats with phlorizin treatment reverses insulin-resistant glucose transport in adipose cells without restoring glucose transporter gene expression. J. Clin. Invest. 87:561-570.

30. Denton, R. M., R. E. Yorke, and P. J. Randle. 1966. Measurement of concentrations of metabolites in adipose tissue and effects of insulin, alloxan diabetes, and adrenaline. Biochem. J. 100:407-419.

31. Shibata, H., F. W. Robinson, T. R. Soderling, and T. Kono. 1991. Effect of okadaic acid on insulin-sensitive cAMP phosphodiesterase in rat adipocytes. Evidence that insulin may stimulate the enzyme by phosphorylation. J. Biol. Chem. 266:17948-17953.

32. Corvera, S., and M. P. Czech. 1985. Mechanism of insulin action on membrane protein recycling: a selective decrease in the phosphorylation state of insulin-like growth factor II receptors in the cell surface. Proc. Natl. Acad. Sci. USA. 82:7314-7318.

33. Wardzala, J. J., I. A. Simpson, M. M. Rechler, and S. W. Cushman. 1984. Potential mechanism of stimulatory action of insulin on insulin-like growth factor II binding to the isolated rat adipose cell. Apparent redistribution of receptors cycling between a larger intracellular pool and the plasma membrane. J. Biol. Chem. 259:8378-8383.

34. Oka, Y., C. Mottola, C. L. Oppenheimer, and M. P. Czech. 1984. Insulin activates the appearance of insulin-like growth factor II receptors on the adipocyte cell surface. Proc. Natl. Acad. Sci. USA. 81:4028-4032.

35. Begum, N., K. E. Sussman, and B. Draznin. 1991. High levels of cytosolic free calcium inhibit dephosphorylation of insulin receptor and glycogen synthase. Cell Calcium. 12:423-430.

36. Clari, G., L. Bordin, G. Marzaro, and V. Moret. 1991. Effect of intracellular $\mathrm{pH}$ changes on the distribution of tyrosine- and serine/threonine-protein kinase activities in human erythrocytes. Biochem. Biophys. Res. Commun. 178:1021-1027. 